\title{
Comparing the severity of disturbance: a meta- analysis of marine macrobenthic community data
}

\author{
R. M. Warwick, K. R. Clarke \\ Plymouth Marine Laboratory, Prospect Place, The Hoe, Plymouth PL1 3DH, United Kingdom
}

\begin{abstract}
A multivariate method of comparing the severity of disturbance to subtidal macrobenthic communities on a common scale is described. Data on species abundances and biomasses from a variety of stations on the NE Atlantic shelf at which the pollution/disturbance status is known have been aggregated to phylum level and the abundance and biomass data merged using an allometric equation to form a 'production' matrix. An ordination (non-metric Multi-Dimensional Scaling, MDS) of all these data, combined in a single meta-analysis, produces a configuration with disturbance as its major axis. These 50 samples can be used as a training data-set against which the status of communities from new studies can be assessed.
\end{abstract}

\section{INTRODUCTION}

The analysis of changes in benthic community structure has now become one of the mainstays for detecting and monitoring the biological effects of marine pollution. Whilst there are now very sensitive multivariate methods for detecting community change (e.g. Gray et al. 1990, Warwick et al. 1990, Warwick \& Clarke 1991, Dawson Shepherd et al. 1992), such changes are usually measured relative to local controls and rather little attention has been paid to assessing the comparative severity of pollution incidents against each other on a regional or global scale. Such an assessment is required if sensible management decisions are to be made.

On initial consideration, measures of community degradation which are independent of the taxonomic identity of the species involved, such as diversity measures either expressed as indices or dominance curves, would be most appropriate for such comparative studies. Species composition varies so much from place to place depending on local environmental conditions that any general species-dependent response to stress would be masked by this variability. However, diversity measures are also sensitive to changes in natural environmental variables and an unperturbed community in one locality could easily have the same diversity as a perturbed community in another. Also, diversity does not behave consistently or predictably in response to environmental stress. Both current theory (Connell 1978, Huston 1979) and empirical observation (e.g. Dauvin 1984) suggest that increasing levels of disturbance may either decrease or increase diversity, and it may even remain the same. A monotonic response would be easier to interpret. Also, diversity measures are much less sensitive than multivariate methods in detecting community change (Gray et al. 1990, Warwick et al. 1990, Warwick \& Clarke 1991, Dawson Shepherd et al. 1992), which is not surprising in view of the much greater amount of information which multivariate analyses retain. Finally, to obtain comparative data on species diversity requires a highly skilled and painstaking analysis of species and an unusually high degree of standardisation with respect to the degree of taxonomic rigour applied to the sample analysis: e.g. it is not valid to compare diversity at one site where one taxon is designated as 'nemertines' with another at which this taxon has been divided into species (Wu 1982).

The ABC (abundance/biomass comparison) method of evaluating the pollution status of macrobenthic communities (Warwick 1986, Warwick et al. 1987) overcomes some of the problems outlined above. It is closer to an absolute measure of disturbance in that there is an internal comparison of the distribution of abundance among taxa and the distribution of biomass 
among taxa in the same sample. Also, it is possible to work at taxonomic levels higher than that of species (Warwick 1988a, b). However, only 3 categories of pollution or disturbance can be unequivocally recognised. unpolluted (or undisturbed), moderately polluted and grossly polluted. There can be some subjective recognition of intermediate conditions (e.g. moderately' grossly polluted), but in any case this method is not particularly sensitive, e.g. when applied to the 'Amoco-Cadiz' oil spill (Ibanez \& Dauvin 1988). Also, intertidally this method may be confounded by the erratic occurrence of large numbers of a small mobile species (Beukema 1988) and also recruitment of spat, although this problem can be at least partially ameliorated by the use of partial dominance curves (Clarke 1990).

It is well known that the various taxa of marine organisms differ in their sensitivity to disturbance, and it is desirable that measures of disturbance should in some way capture and utilise this information. As multivariate methods do this they are more sensitive. Here we develop a multivariate method of comparing the severity of disturbance at physically different and geographically distant sites on a single scale of severity, which overcomes the problems noted above to a greater or lesser degree. The 2 perceived disadvantages of multivariate methods are their sensitivity to natural differences in species composition, as noted above, and the fact that it is difficult to place a value judgement on the observed change. Multivariate methods simply demonstrate change, with no indication as to whether this can be regarded as 'deleterious'.

The first of these problems can be overcome by working at taxonomic levels higher than species. The taxonomic composition of natural communities tends to become increasingly similar at these higher levels. Although 2 communities may have no species in common, they will almost certainly comprise the same phyla. For soft-bottom marine benthos, perhaps one of the more remarkable findings of recent studies has been that disturbance effects are detectable with multivariate methods at the highest taxonomic levels (Heip et al. 1988, Warwick 1988a, b, Ferraro \& Cole 1990), even in some instances where these effects are rather subtle and are not evidenced in univariate measures even at the species level. Two examples will serve to illustrate this point.

Dauvin (1984, Annexe 3.2) sampled the macrobenthos at station 'Pierre Noire' in the Bay of Morlaix, on the Brittany coast of France, on 21 occasions at roughly 3 mo intervals between April 1977 and February 1982. This sampling spanned the period of the oil spill resulting from the wreck of the 'Amoco-Cadiz', some $50 \mathrm{~km}$ west of the station, which occurred in March 1978. Species diversity $H^{\prime}$ (Fig. 1A) and its components of species rich- ness and evenness all tended to increase after the spill, and remained at a higher level than the pre-spill condition. Non-metric Multi-Dimensional Scaling ordination (MDS) of the 4 th root-transformed species abundance data showed an immediate post-spill change in community composition with a gradual evolution of the community back towards the pre-spill condition, but arriving at a new 'equilibrium' structure which was different from the pre-spill one (Fig. 1B). With the species data aggregated into just 5 phyla (Annelida, Crustacea, Mollusca, Echinodermata and 'Others') the MDS configuration is very similar, but if anything, the post-spill change in community structure was more marked and the recovery towards the pre-spill condition more linear (Fig. 1C).

The second example concerns macrobenthos sampled in concentric zones around the Ekofisk oil-field in the North Sea (Gray et al. 1990). Diversity was only significantly reduced in the inner zone, $<250 \mathrm{~m}$ from the centre of drilling activity, with no significant differences in diversity between the 3 outer zones 250-1000, $1000-3500$ and $>3500 \mathrm{~m}$ (Fig. 1D). However, the species level MDS shows a clear gradation of community structure from the inner to outer zones (Fig. 1E) and formal statistical tests reveal a significant difference even between the 2 outer zones. The statistical significance of this difference is even apparent when the species data have been aggregated to phylum level (Fig. 1F).

A solution to the second perceived weakness of multivariate methods, their inability to attach a scale of 'importance' to observed community change, has emerged from the meta-analysis described below.

\section{META-ANALYSIS OF PHYLUM LEVEL DATA}

Meta-analysis is a term widely used in biomedical statistics and refers to the combined analysis of a range of individual case-studies which in themselves are of limited value but in combination provide a more global insight into the problem under investigation. Here we have combined macrobenthic data aggregated to phyla from a range of case-studies relating to varying types of disturbance, and also from sites which are regarded as unaffected by such perturbations. We wished to choose the most ecologically meaningful units in which to work, being mindful of the fact that abundance is a rather poor measure of such relevance, biomass is better and production is perhaps the most relevant of all. Of course, no studies have measured production $(P)$ of all species within a community, but many studies provide both abundance $(A)$ and biomass $(B)$ data. We have therefore approximated production using the allometric equation:

$$
P=(B / A)^{0.73} \times A
$$



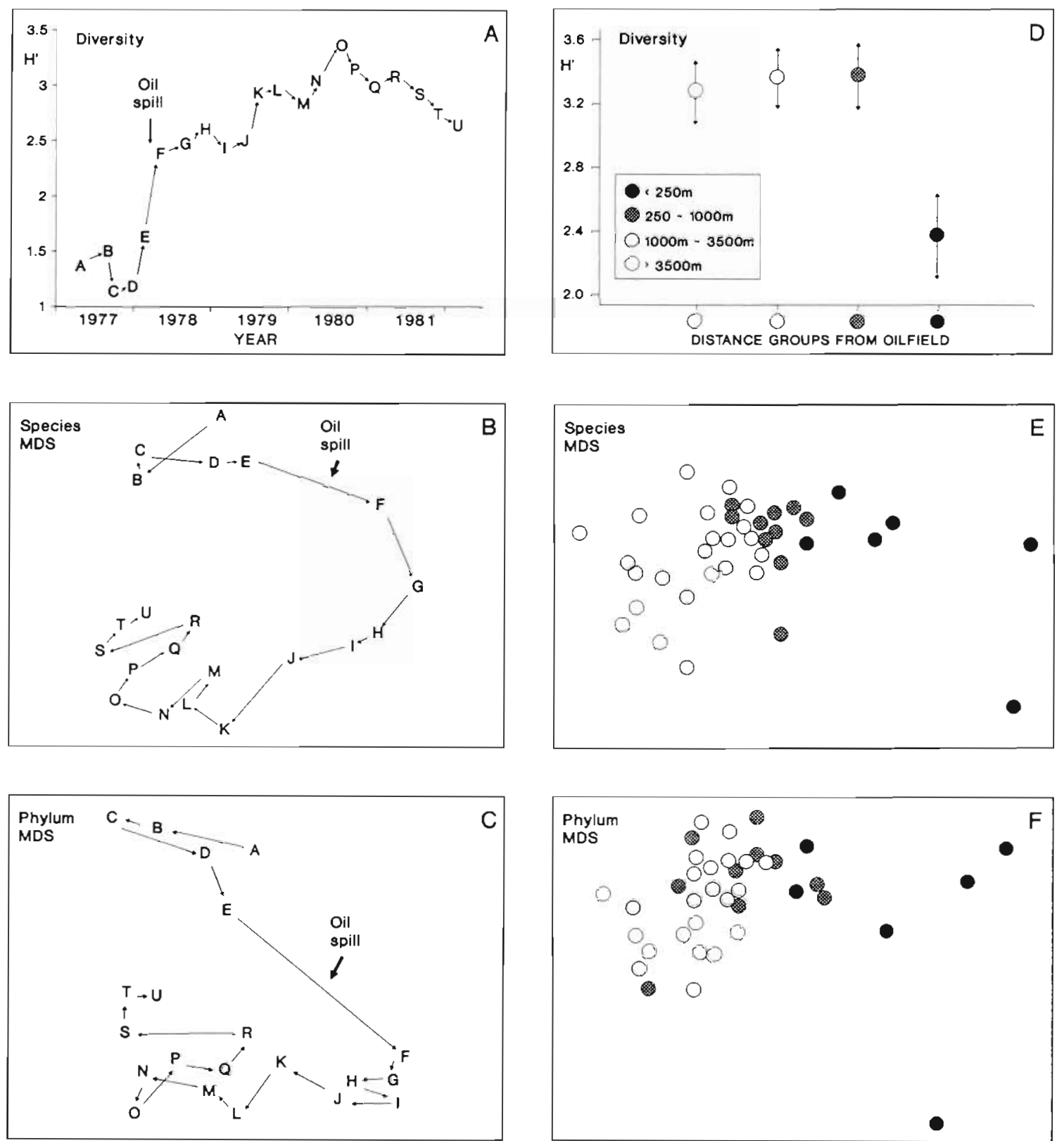

Fig. 1. (A to C) Bay of Morlaix macrobenthos ('Amoco-Cadiz' oil spill): (A) Shannon diversity at approximately 3 mo intervals; (B) MDS ordination by time intervals of species abundance data; (C) MDS ordination of phylum data. (D to F) Ekofisk oil-field macrobenthos: (D) Shannon diversity (mean and $95 \%$ confidence intervals) in each distance zone; (E) MDS ordination by stations of species abundance data [distance zones coded as in (D)]; (F) MDS ordination of phylum abundances. All MDS analyses use Bray-Curtis similarities on 4 th root-transformed data. Stress values are: (B) 0.09 ; (C) 0.07 ; (E) 0.12 ; (F) 0.13

$B / A$ is of course the mean body-size, and 0.73 is the average exponent of the regression of annual production on body-size for macrobenthic invertebrates derived by Brey (1990). Brey found that in the 3 phyla for which sufficient data were available the exponent was different $(0.88$ for polychaetes, 0.64 for crustaceans and 0.72 for molluscs). However, we found that the use of these individual exponents plus the mean value of 0.73 for the remaining phyla made no differ- ence to the meta-analysis described below, and so for simplicity a common exponent was used for all phyla. Since the data from each study are standardised (i.e. production of each phylum is expressed as a proportion of the total) the intercept of this regression is irrelevant. For each data set the abundance and biomass data were first aggregated to phyla following the classification of Howson (1987). The 20 phyla used are given in Table 1 . Although only 14 of these were en- 
Table 1. List of phyla used in the species aggregation. "Phylum not encountered in this study

\begin{tabular}{|rlrl|}
\hline 1 & Porifera & 11 & Annelida \\
2 & Cnidaria & 12 & Chelicerata \\
3 & Platyhelminthes & 13 & Crustacea \\
4 & Nemertea & 14 & Mollusca \\
5 & Nematoda & 15 & Brachyopoda \\
6 & Priapulida & 16 & Bryozod \\
7 & Entoprocta & 17 & Phoronida \\
8 & Pogonophora & 18 & Echinodermata \\
9 & Sipunclua & 19 & Hemichordata \\
10 & Ehiura & 20 & Chordata \\
\hline
\end{tabular}

countered in the present exercise (Table 2), all remaining phyla which are likely to occur in the macrobenthos are included for the purpose of evaluating new data (see below). The abundance and biomass matrices were then combined to form a 'production' matrix using the above formula. All data sets were then merged into a single production matrix and an MDS performed on the standardised, 4 th roottransformed data using the Bray-Curtis similarity measure. We have not been selective about the data used, and have included all macrobenthic studies from a single region (the NE Atlantic Shelf) for which both abundance and biomass data were available to us. These are as follows:

(1) Clyde sewage-sludge dump-ground. A transect of 12 stations sampled in 1983 on a west-east transect across a sewage sludge dump-ground in the Firth of Clyde, Scotland (Pearson \& Blackstock 1984). Stations in the middle of the transect show clear signs of gross pollution (Pearson 1987. Warwick et al. 1987).

(2) Lochs Linnhe and Eil. A time series of samples from 1963 to 1973 at stations in 2 western Scottish sealochs, Lochs Linnhe and Eil, covering the period of commissioning of a pulp-mill (Pearson 1975). The later years show increasing pollution effects on the macrofauna, except that in 1973 a recovery was noted in Loch Linnhe following a decrease in pollution loading (Pearson 1975, Warwick 1986).

(3) Oslofjord. Samples collected at 6 stations in Frierfjord/Langesundfjord (connecting to Oslofjord), Norway (Gray et al. 1988). The stations were ranked in order of increasing stress, A-G-E-D-B-C, based on 13 different criteria (their Table 2). The macrofauna at Stns B, C and D were considered to be influenced by seasonal anoxia in the deeper basins of the fjord.

(4) Bay of Morlaix ('Amoco-Cadiz' oil spill); see above. In view of the large number of observations, the 21 sampling occasions have been aggregated into years for the meta-analysis: $1977=$ pre-spill, $1978=$ immediate post-spill and 1979-1981 = recovery period.

(5) Skagerrak. Two stations in the Skagerrak at depths of 100 and $300 \mathrm{~m}$ (Josefson 1981). The $300 \mathrm{~m}$ station showed signs of disturbance attributable to the dominance of the sediment-reworking bivalve Abra nitida (Josefson 1981, Warwick et al. 1987).

(6) Northumberland. An undisturbed station off the coast of Northumberland, NE England (Buchanan \& Warwick 1974).

(7) Carmarthen. An undisturbed station in Carmarthen Bay, southern Wales (Warwick et al. 1978).

(8) Kiel Bay. An undisturbed station in Kiel Bay, Germany; mean of 22 sets of samples at the control station for the experimental study of Arntz \& Rumohr (1982).

In all, this gives a total of 50 samples, the disturbance status of which has been assessed by a variety of different methods including univariate indices, dominance plots, $\mathrm{ABC}$ curves, measured contaminant concentrations, etc.

The MDS for all samples (Fig. 2) takes the form of a wedge with the pointed end to the right and the wide end to the left. It is immediately apparent that the long axis of the configuration represents a scale of disturbance, with the most disturbed samples to the right and the undisturbed samples to the left. (The reason for the spread of sites on the vertical axis is less obvious, and will be dealt with later.) The relative positions of samples on the horizontal axis can thus be used as a measure of the relative severity of disturbance. Another gratifying feature of this plot is that in all cases increasing levels of disturbance result in a shift in the same direction, i.e. to the right. For visual clarity, the samples from individual case studies have been plotted in Fig. $3 \mathrm{~A}$ to $\mathrm{C}$, with the remaining samples represented as dots.

(1) Clyde sewage-sludge dump-ground. Samples taken along this transect span the full scale of the long axis of the configuration (Fig. 3A). Stations at the 2 extremities of the transect (Stns $1 \& 12$ ) are at the extreme left of the wedge, and stations close to the dump centre (Stns $6 \&$ 7) are at the extreme right.

(2) Lochs Linnhe and Eil. In the early years (1963 to 1968 ) both stations are situated at the unpolluted left-hand end of the configuration (Fig. 3B). After this the Loch Eil station moves towards the right, and at the end of the sampling period (1973) it is close to the right-hand end; only the sites at the centre of the Clyde dump-site are more polluted. The Loch Linnhe station is rather less affected and the previously discussed recovery in 1973 is evidenced by the return to the lefthand end of the wedge.

(3) Oslofjord. The left-to-right sequence of stations in the meta-analysis is A-G-E-D-B-C (Fig. 3C), exactly the ranking given by Gray et al. (1988) in order of increasing stress. Note that the 3 stations affected by seasonal anoxia ( $S$ tns B, C \& D) are well to the right of the other three, but are not as severely disturbed as the organically enriched sites in (1) and (2) above. 
Table 2. Proportion (\%) of total 'production' contributed by each phylum for all 50 samples used in the meta-analysis Cnid: Cnidaria; Plat: Platyhelminthes; Neme: Nemertea; Nema: Nematoda; Pria: Priapulida; Sipu: Sipuncula; Anne: Annelida Chel: Chelicerata; Crus: Crustacea; Moll: Mollusca; Phor: Phoronida; Echi: Echinodermata; Hemi: Hemichordata; Chor: Chordata

\begin{tabular}{|c|c|c|c|c|c|c|c|c|c|c|c|c|c|c|}
\hline \multirow[t]{2}{*}{ Site } & \multicolumn{14}{|c|}{ Phylum } \\
\hline & Cnid & Plat & Neme & Nema & Pria & Sipu & Anne & Chel & Crus & Moll & Phor & Echi & Hemi & Chor \\
\hline \multicolumn{15}{|c|}{ Clyde } \\
\hline 1 & 0 & 0 & 0 & 0 & 0 & 0 & 7.0 & 0 & 0.7 & 89.9 & 0 & 2.4 & 0 & 0 \\
\hline 2 & 0 & 0 & 5.4 & 0 & 0 & 0 & 63.8 & 0 & 0 & 22.2 & 0 & 8.6 & 0 & 0 \\
\hline 3 & 0.3 & 0 & 7.0 & 0.2 & 0 & 0 & 63.2 & 0 & 6.2 & 21.8 & 0 & 1.4 & 0 & 0 \\
\hline 4 & 0 & 0.2 & 0.7 & 0 & 0 & 0 & 63.2 & 0 & 0 & 34.4 & 0 & 1.5 & 0 & 0 \\
\hline 5 & 0 & 0 & 0 & 1.1 & 0 & 0 & 90.1 & 0 & 0 & 8.8 & 0 & 0 & 0 & 0 \\
\hline 6 & 0 & 0 & 0 & 37.8 & 0 & 0 & 62.2 & 0 & 0 & 0 & 0 & 0 & 0 & 0 \\
\hline 7 & 0 & 0 & 0 & 0.9 & 0 & 0 & 99.1 & 0 & 0 & 0 & 0 & 0 & 0 & 0 \\
\hline 8 & 0.3 & 0 & 0.4 & 0.4 & 0 & 0 & 88.2 & 0 & 0 & 10.7 & 0 & 0 & 0 & 0 \\
\hline 9 & 0 & 0 & 0 & 0 & 0 & 0 & 83.5 & 0 & 0 & 16.5 & 0 & 0 & 0 & 0 \\
\hline 10 & 0 & 0 & 2.8 & 0 & 0 & 0 & 63.1 & 0 & 0 & 12.5 & 0 & 21.6 & 0 & 0 \\
\hline 11 & 0.8 & 0 & 0 & 0 & 0 & 0 & 32.8 & 0 & 13.3 & 49.4 & 0 & 3.6 & 0 & 0 \\
\hline 12 & 0 & 0 & 0 & 0 & 0 & 0 & 10.4 & 0 & 0 & 65.2 & 0 & 23,5 & 0.8 & 0 \\
\hline \multicolumn{15}{|c|}{ Loch Linnhe } \\
\hline 63 & 0 & 0 & 1.5 & 0.1 & 0 & 0 & 26.3 & 0 & 0 & 61.5 & 0 & 10.7 & 0 & 0 \\
\hline 64 & 0 & 0 & 0 & 0 & 0 & 0.1 & 11.8 & 0 & 0 & 21.8 & 0 & 66.2 & 0 & 0 \\
\hline 65 & 0 & 0 & 0.1 & 0 & 0 & 0 & 27.3 & 0 & 0 & 7.1 & 0 & 65.5 & 0 & 0 \\
\hline 66 & 0 & 0 & 1.5 & 0 & 0 & 0.4 & 54.1 & 0 & 0 & 34.6 & 0 & 9.1 & 0.4 & 0 \\
\hline 67 & 0 & 0 & 1.8 & 0 & 0 & 0 & 31.0 & 0 & 0 & 51.8 & 0 & 15.2 & 0.1 & 0 \\
\hline 68 & 0 & 0 & 4.1 & 0 & 0 & 0.3 & 46.4 & 0 & 0 & 39.6 & 0 & 8.7 & 0.9 & 0 \\
\hline 69 & 1.5 & 0 & 3.8 & 0 & 0 & 0.4 & 62.2 & 0 & 0 & 21.2 & 0 & 10.7 & 0.2 & 0 \\
\hline 70 & 2.1 & 0 & 0 & 0.3 & 0 & 0 & 83.2 & 0 & 0 & 5.4 & 0 & 9.0 & 0 & 0 \\
\hline 71 & 1.1 & 0 & 0.6 & 0.3 & 0 & 0 & 96.7 & 0 & 0 & 0.9 & 0 & 0.4 & 0 & 0 \\
\hline 72 & 0 & 0 & 1.2 & 0.9 & 0 & 0 & 86.0 & 0 & 0 & 7.4 & 0 & 4.5 & 0 & 0 \\
\hline 73 & 0.1 & 0 & 2.9 & 0 & 0 & 0 & 26.4 & 0 & 0 & 55.0 & 0 & 15.6 & 0 & 0 \\
\hline \multicolumn{15}{|c|}{ Loch Eil } \\
\hline 63 & 0.1 & 0 & 0.5 & 0 & 0 & 0.1 & 37.0 & 0 & 0.7 & 55.8 & 0 & 5.8 & 0 & 0 \\
\hline 64 & 0 & 0 & 0.2 & 0 & 0 & 1.3 & 34.7 & 0 & 0.9 & 55.6 & 0 & 7.3 & 0 & 0 \\
\hline 65 & 0 & 0 & 0 & 0 & 0 & 1.1 & 45.9 & 0 & 1.8 & 45.5 & 0 & 5.7 & 0 & 0 \\
\hline 66 & 0 & 0 & 0.8 & 0 & 0.3 & 3.1 & 61.6 & 0 & 3.9 & 23.0 & 0 & 7.2 & 0 & 0 \\
\hline 67 & 0 & 0 & 0.6 & 0 & 0 & 0.7 & 31.2 & 0 & 0.1 & 59.8 & 0 & 7.6 & 0 & 0 \\
\hline 68 & 0.3 & 0 & 0.4 & 0 & 1.2 & 0.4 & 42.1 & 0 & 0 & 54.4 & 0 & 1.1 & 0 & 0 \\
\hline 69 & 1.2 & 0 & 1.8 & 0 & 0 & 0 & 43.4 & 0 & 0 & 53.6 & 0 & 0 & 0 & 0 \\
\hline 70 & 1.0 & 0 & 0.9 & 0 & 0 & 0.1 & 74.0 & 0 & 0 & 23.9 & 0 & 0.1 & 0 & 0 \\
\hline 71 & 0.4 & 0 & 0.2 & 1.0 & 0 & 0 & 96.6 & 0 & 0 & 1.8 & 0 & 0 & 0 & 0 \\
\hline 72 & 0 & 0 & 0.4 & 5.9 & 0 & 0 & 64.4 & 0 & 0 & 29.3 & 0 & 0 & 0 & 0 \\
\hline 73 & 0 & 0 & 0 & 0.3 & 0 & 0 & 98.8 & 0 & 0 & 0.9 & 0 & 0 & 0 & 0 \\
\hline \multicolumn{15}{|c|}{ Oslofjord } \\
\hline A & 0 & 0 & 5.8 & 0 & 0 & 0 & 20.5 & 0 & 0.7 & 12.7 & 0 & 60.2 & 0 & 0 \\
\hline B & 0 & 0 & 0.7 & 0 & 0 & 0 & 83.7 & 0 & 7.9 & 7.6 & 0 & 0 & 0 & 0 \\
\hline C & 0 & 0 & 0.7 & 0 & 0 & 0 & 83.9 & 0 & 0.3 & 15.1 & 0 & 0 & 0 & 0 \\
\hline D & 0 & 0 & 0.2 & 0 & 0 & 0 & 66.5 & 0 & 0.1 & 33.1 & 0 & 0.1 & 0 & 0 \\
\hline$E$ & 5.9 & 0 & 1.2 & 0 & 0 & 0.2 & 29.6 & 0 & 0 & 45.6 & 0 & 17.4 & 0 & 0 \\
\hline $\mathrm{G}$ & 0.9 & 0 & 0.3 & 0 & 0 & 0 & 8.2 & 0 & 0 & 39.6 & 0 & 51.0 & 0 & 0 \\
\hline \multicolumn{15}{|c|}{ Bay of Morlaix } \\
\hline 77 & 0.1 & 0 & 1.4 & 0 & 0 & 0.7 & 29.3 & 0 & 59.1 & 8.6 & 0 & 0.9 & 0 & 0 \\
\hline 78 & 0.1 & 0 & 2.2 & 0 & 0 & 1.2 & 75.8 & 0 & 1.8 & 18.9 & 0 & 0.1 & 0 & 0 \\
\hline 79 & 0.4 & 0 & 0.5 & 0 & 0 & 2.3 & 54.2 & 0.1 & 7.6 & 34.1 & 0 & 0.9 & 0 & 0.1 \\
\hline 80 & 0.1 & 0 & 0.6 & 0 & 0 & 1.3 & 55.3 & 0 & 8.5 & 31.5 & 0 & 2.8 & 0 & 0.1 \\
\hline 81 & 0.2 & 0 & 1.4 & 0 & 0 & 0.9 & 51.8 & 0.1 & 15.8 & 23.4 & 0 & 6.5 & 0 & 0.1 \\
\hline \multicolumn{15}{|c|}{ Skagerrak } \\
\hline 10 & 0 & 0.2 & 0.6 & 0 & 0 & 0 & 56.4 & 0 & 3.1 & 2.0 & 0 & 37.6 & 0.1 & 0 \\
\hline 31 & 0.1 & 0 & 1.1 & 0 & 0 & 0.9 & 70.6 & 0 & 0.5 & 22.2 & 0 & 4.5 & 0 & 0 \\
\hline \multicolumn{15}{|c|}{ Northumberland } \\
\hline$N$ & 0.5 & 0.6 & 0.9 & 0 & 0 & 0 & 58.0 & 0 & 26.4 & 5.4 & 0 & 7.8 & 0.5 & 0 \\
\hline \multicolumn{15}{|c|}{ Carmarthen } \\
\hline CR & 0 & 0 & 0.2 & 0 & 0 & 0 & 18.5 & 0 & 2.5 & 71.4 & 0.1 & 7.2 & 0 & 0 \\
\hline \multicolumn{15}{|c|}{ Kiel Bay } \\
\hline $\mathrm{K}$ & 0 & 0 & 0 & 0 & 0 & 0 & 33.8 & 0 & 16.9 & 47.6 & 0 & 1.7 & 0 & 0 \\
\hline
\end{tabular}




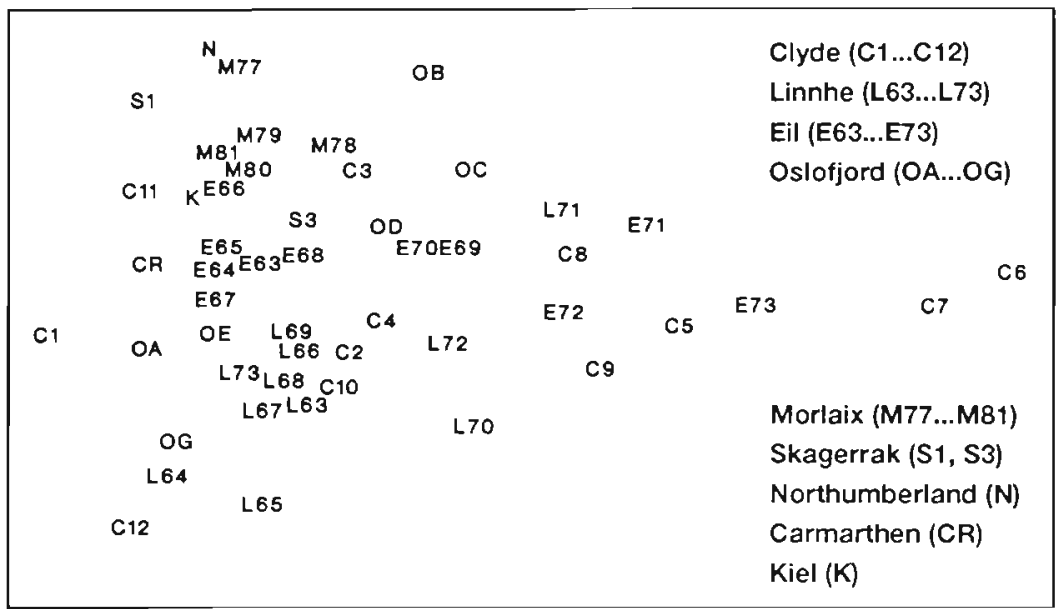

Fig. 2. Two-dimensional MDS ordination of phylum level 'production' data from all studies. Stress $=0.16$
(4) Bay of Morlaix. Note the shift to the right between 1977 (pre-spill) and 1978 (post-spill), and the subsequent return to the left in 1979 to 1981 (Fig. 3C). However, the shift is relatively small and this must be regarded as only a mild effect.

(5) Skagerrak. The biologically disturbed $300 \mathrm{~m}$ station is well to the right of the undisturbed $100 \mathrm{~m}$ station, although the former is still quite close to the left-hand end of the wedge.

(6 to 8) Unpolluted sites. The Northumberland, Carmarthen Bay and Kiel Bay stations are all situated at the left-hand end of the wedge.

It is important with any 2-dimensional (2-d) ordination to assess how accurately it preserves betweensample relationships in this low-dimensional space; a 2 -d picture can sometimes be misleading if the community patterns are complex. Here we have used Kruskal's stress formula 1, which is a scaled sum of squared differences between distances in the MDS plot and their fitted values under Kruskal's non-metric scaling procedure (Kruskal \& Wish 1978). The stress value for the 2 -d MDS is 0.16 , indicating a usable description which, though not perfect, is unlikely to mislead. The implications of particular stress values for adequacy of an ordination in a specific number of dimensions are discussed by, for example, Spence \& Graef (1974). The 3-d MDS (Fig. 4) has a somewhat lower stress value of 0.11 ; note that stress values always decrease with increasing dimensionality of the ordination space. It can be seen that the 'wedge' is replaced by a 'cone' in which the major axis is again clearly identifiable as the pollution/disturbance axis. (Note that all samples were used in constructing the 3 d MDS but some contiguous points have been removed from Fig. 4, for clarity of display.) In fact, the projection of the 3-d MDS onto the base plane shown in Fig. 4 yields a picture which is not materially different from the 2-d MDS of Fig. 2. The third axis mainly accommodates a small number of samples which were a little
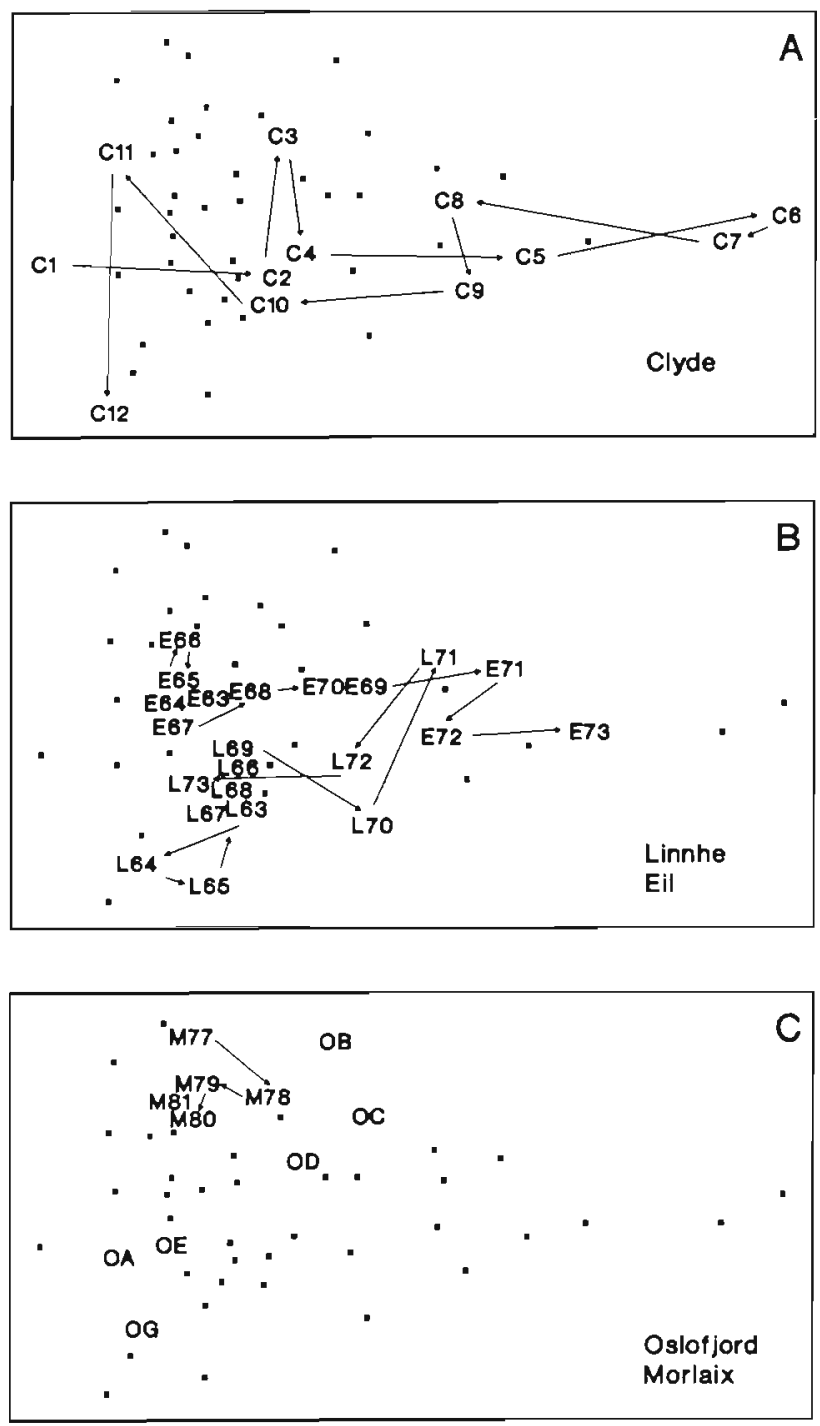

Fig. 3. As in Fig. 2 but with individual studies highlighted: (A) Clyde dump-ground; (B) Loch Linnhe and Loch Eil; (C) Oslofjord and Bay of Morlaix 


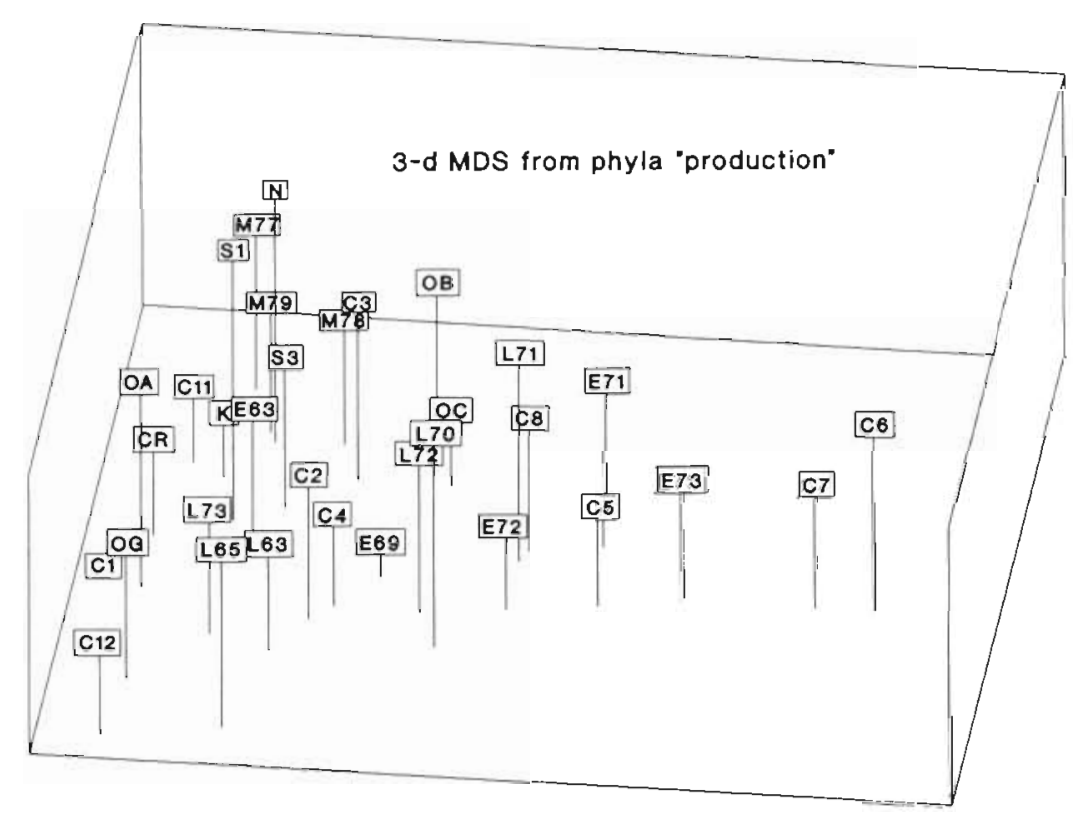

Fig. 4. Three-dimensional MDS ordination of phylum level 'production' data from all studies (annotation as in Fig. 2). Stress $=0.11$

to echinoderms, molluscs and crustaceans (e.g. Rosenberg 1972). By superimposing on the meta-analysis symbols scaled in size according to the proportional representation of individual phyla, it is possible to visualise the contribution made by each phylum to the overall configuration (Fig. 6). By and large, these conform with our intuitive undertanding of the relative tolerances of different phyla. Annelids comprise a high proportion of the total 'production' at the polluted end of the wedge, with a decrease at the least polluted sites (Fig. 6A). Molluscs are also present at all sites, except the 2 most polluted, and have increasingly higher dominance towards the non-polluted end of the wedge (Fig. 6B). Echinoderms are even more concentrated at the non-polluted end, with some tendency for higher dominance at the bottom of the configuration (Fig. 6C). Crustacea are again concentrated to the left, but this

more difficult to place accurately at the unpolluted end of the wedge, for example N, C1 and K. The 3-d analysis provides reassurance, at least for the current training data, that the 2-d wedge is an adequate summary of the sample relationships on which to base inference about relative community change. The following discussion therefore centres on the 2-d configuration.

\section{NATURAL ENVIRONMENTAL VARIABILITY}

An initial premise of this method is that, at the phylum level, the taxonomic composition of communities is relatively less affected by natural environmental variables than by pollution or disturbance. To test this we have superimposed symbols scaled in size according to the values of the 2 most important environmental variables considered to influence community structure, sediment grain size and water depth, onto the meta-analysis MDS configuration (Fig. 5). If these variables were influencing the configuration to any degree, then samples with similar values for these variables should cluster together. However, both variables are quite randomly distributed, which supports our original assumption.

\section{DISTRIBUTION OF INDIVIDUAL PHYLA}

That the phyletic composition of communities is modified by pollution is already well known, in particular the relative tolerance of annelids in comparison time completely confined to the top part of the configuration (Fig. 6D). Clearly, the differences in relative proportions of crustaceans and echinoderms are largely responsible for the vertical spread of samples at
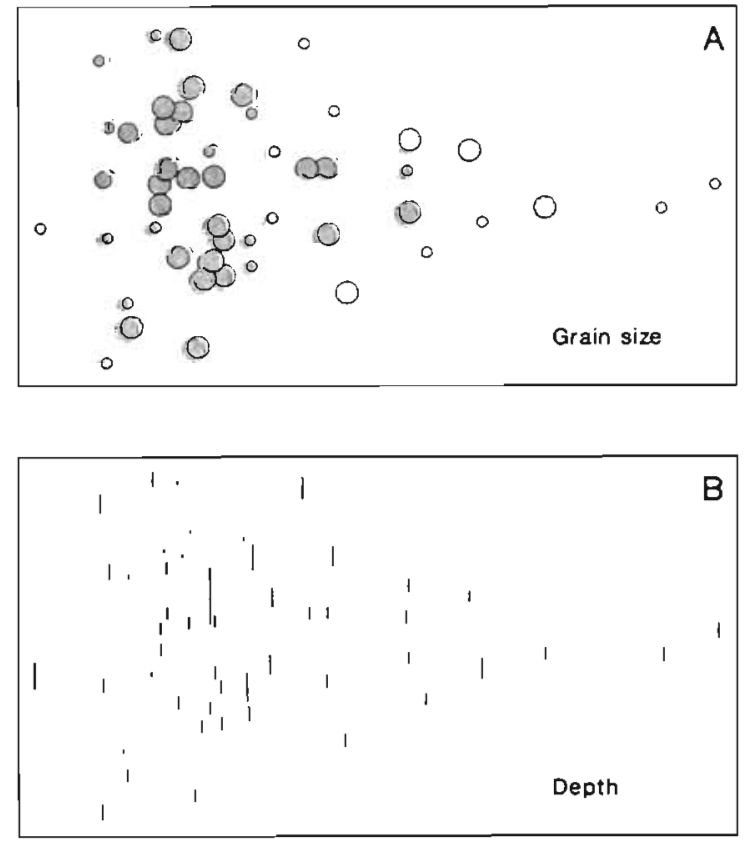

Fig. 5. MDS configuration from Fig. 2 with symbols scaled in size to show values of measured environmental variables at the sample locations: (A) circle diameter represents Wentworth grades of sediment, ranging from silt to fine sand;

(B) bar height gives water depth (range 13 to $300 \mathrm{~m}$ ) 

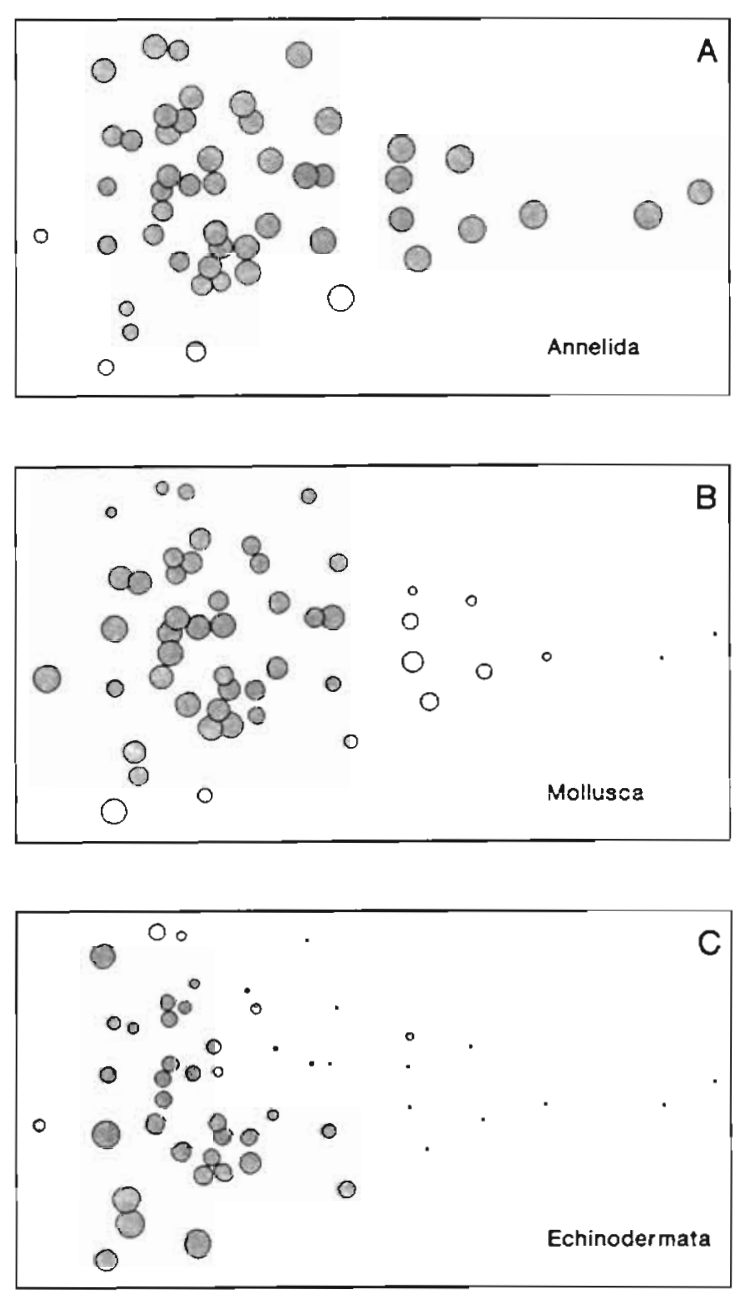

this end of the wedge, but these differences cannot be explained in terms of the effects of any recorded natural environmental variables. Nematoda are clearly more important at the polluted end of the wedge (Fig. 6E), an obvious consequence of the fact that species associated with organic enrichment tend to be very large in comparison with their normal meiofaunal counterparts (e.g. Oncholaimids), and are therefore retained on the macrofaunal ecologists' sieves. Other less important phyla show no clear distribution pattern, except that most are absent from the extreme right-hand samples.

\section{CONCLUSIONS}

This multivariate approach to the comparative scaling of benthic community responses to environmental stress seems to be more satisfactory than taxonindependent methods, having both generality and consistency of behaviour. It is difficult to assess the sensitivity of the technique because data on abundance and biomass of phyla are not available for any
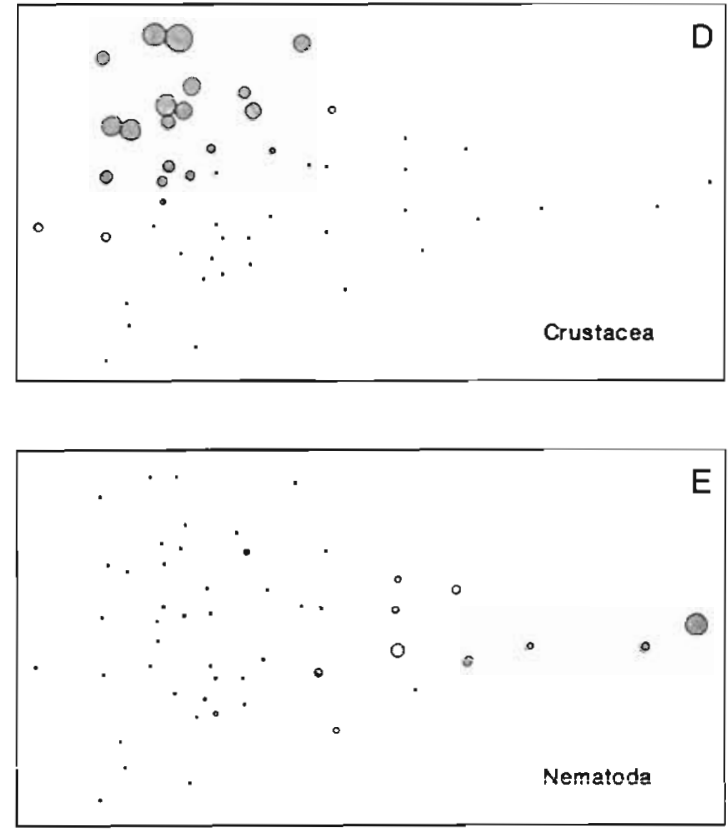

Fig. 6. MDS configuration from Fig. 2 with circles scaled in size to represent proportions of individual phyla at the sample locations (from transformed production' data): (A) Annelida; (B) Mollusca; (C) Echinodermata; (D) Crustacea; (E) Nematoda. Dots denote absence of phylum at that location

really low-level or subtle perturbations. However, its ability to detect the deleterious effect of the 'AmocoCadiz' oil spill, where diversity was not impaired, and to rank the Frierfjord/Langesundfjord samples correctly with respect to levels of stress which had been determined by a wide variety of more time-consuming species-level techniques, suggests that this approach may retain much of the sensitivity of multivariate methods discussed earlier. It certainly seems, at least, that there is a high signal/noise ratio in the sense that natural environmental variation does not affect the communities at this phyletic level to an extent which masks the response to perturbation. This approach clearly scores in terms of cost effectiveness, with only phylum level identification being required.

Interpretation of the ranking of sites on the long axis of the wedge, as a reflection of increasing disturbance or community degradation, is based on a variety of information in the univariate and graphical distribution categories, contaminant concentrations, etc., which are only weakly linked to the multivariate analysis itself and are not directly comparable between the 
component studies. It would not be possible to scale this axis in terms of, say, the concentration of some particular pollutant, because the component studies represent a range of different chemical, biological and physical types of perturbation.

The fact that this meta-analysis 'works' presently has a rather weak theoretical basis. Why should Mollusca as a phylum be more sensitive to perturbation than Annelida, for example? The answer to this is unlikely to be straightforward and would need to be addressed by considering a broad range of toxicological, physiological and ecological characteristics which are more consistent within than between phyla.

\section{EVALUATION OF NEW DATA}

As presented, the application of these findings to the evaluation of data from new situations requires that both abundance and biomass data are available. We found that the use of abundance data alone produced a less satisfactory ranking of samples with respect to their disturbance status along the principal MDS axis. The use of biomass data alone was rather more satisfactory, but the use of these data combined to estimate the relative 'production' of each phylum gave the most satisfactory result and is regarded as the most ecologically relevant measure.

The scale of perturbation is determined by the 50 samples present in the meta-analysis. These can be regarded as the training set (Table 2) against which the status of new samples can be judged. The best way to achieve this would be to merge the new data with the training set to generate a single production matrix for a re-run of the MDS analysis. The positions of the new data in the 2-dimensional configuration, especially their location on the principal axis, can then be noted. Of course the positions of the samples in the training set may then be altered relative to each other, though such re-adjustments would be expected to be small. It is also natural, at least in some cases, that each new data set should add to the body of knowledge represented in the meta-analysis, by becoming part of an expanded training set against which further data are assessed.

This approach would preserve the theoretical superiority and practical robustness of applying MDS (Clarke \& Green 1988) in preference to ordination methods such as PCA. However, such a strategy could be computationally demanding and there are certain circumstances in which more approximate methods might be appropriate, such as when the number of new data points is very large, no computer is available or when it is preferable to leave the training data set unmodified. Fortunately, because of the relatively low dimensionality of the multivariate space (14 phyla, of which only half are of significance). a 2-dimensional PCA of the 'production' data gives a plot which is rather close to the MDS solution (Fig. 7). The eigenvectors for the first 3 principal components, which together explain $72 \%$ of the total variation, are given in Table 3 . The value of the PC1 score for any existing or new sample can easily be calculated from the first column of this table, without the use of a computer. This score could, with certain caveats (see below), be interpreted as a disturbance index. This index is on a continuous scale but, on the basis of the present training data set, samples with a score of greater than +1 can be regarded as grossly disturbed, those with a value between -0.2 and +1 as exhibiting some evidence of disturbance and those with values less than -0.2 as not signalling disturbance with this methodology. A more robust, though less incisive, interpretation would place less reliance on the absolute location of samples on the MDS or PCA plots and emphasise the movement (to the right) of putatively impacted samples relative to appropriate controls. For a new study, the spread of sample positions in the meta-analysis allows one to scale the importance of observed changes, in the context of differences between control and impacted samples for the training set.

It is perhaps premature, however, to make a positive recommendation that new data sets should be evaluated in either of the above ways. The training data is

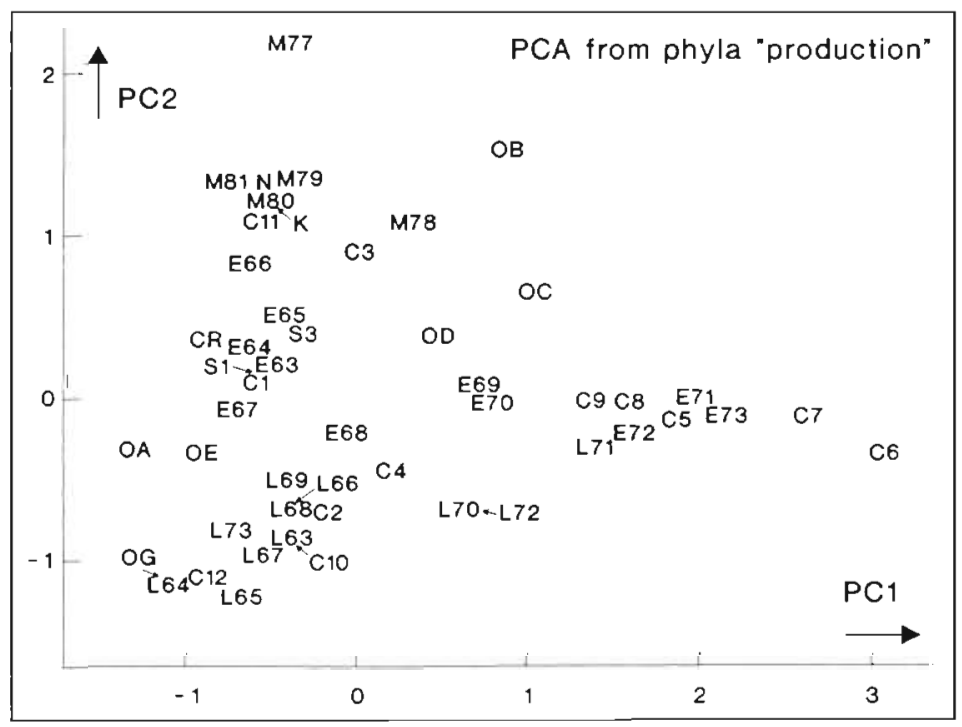

Fig. 7. Two-dimensional PCA ordination of phylum level 'production' data from all studies. Data were standardised and 4 th root-transformed, as for the MDS analysis, before applying covariance-based PCA. The \% variation explained by Axis 1 is $38 \%$ and by Axis 2 is $22 \%$ 
Table 3. Eigenvectors for the first 3 principal components from covariance-based PCA of standardised and 4 th root-transformed phylum 'production' (all samples)

\begin{tabular}{|lrrr|}
\hline Phylum & PC1 & PC2 & PC3 \\
\hline Cnidaria & -0.039 & 0.094 & 0.039 \\
Platyhelminthes & -0.016 & 0.026 & -0.105 \\
Nemertea & -0.169 & 0.026 & 0.061 \\
Nematoda & 0.349 & -0.127 & -0.166 \\
Priapulida & -0.019 & 0.010 & 0.003 \\
Sipuncula & -0.156 & 0.217 & 0.105 \\
Annelida & 0.266 & 0.109 & -0.042 \\
Chelicerata & -0.004 & 0.013 & -0.001 \\
Crustacea & -0.265 & 0.864 & -0.289 \\
Mollusca & -0.445 & -0.007 & 0.768 \\
Phoronida & -0.009 & 0.005 & 0.008 \\
Echinodermata & -0.693 & -0.404 & -0.514 \\
Hemichordata & -0.062 & -0.067 & -0.078 \\
Chordata & -0.012 & 0.037 & -0.003 \\
\hline
\end{tabular}

unlikely to be fully representative of all types of perturbation that could be encountered. For example, all the grossly polluted samples presently involve organic enrichment of some kind, which is conducive to the occurrence of the large nematodes which play some part in the positioning of these samples at the extreme right of the meta-analysis MDS or PCA. This may not happen with communities subjected to toxic chemical contamination only. Also, we have only used data from the NE European shelf, and the applicability of our findings to other geographical regions remains to be investigated.

\section{LITERATURE CITED}

Arntz, W. E., Rumohr, H. (1982). An experimental study of macrobenthic colonization and succession, and the importance of seasonal variation in temperate latitudes. J. exp. mar. Biol. Ecol. 64: 17-45

Beukema, J. J (1988). An evaluation of the ABC-method (abundance/biomass comparison) as applied to macrozoobenthic communities living on tidal flats in the Dutch Wadden Sea. Mar. Biol. 99: 425-433

Brey, T (1990). Estimating productivity of macrobenthic invertebrates from biomass and mean individual weight. Meeresforsch. 32: 329-343

Buchanan, J. B., Warwick, R. M. (1974). An estimate of benthic macrolauna production in the offshore mud of the Northumberland coast. J. mar. biol. Ass. U.K. 54: 197-222

Clarke, K. R. (1990). Comparisons of dominance curves. J. exp. mar. Biol. Ecol. 138: 143-157

Clarke, K. R., Green, R. H. (1988). Statistical design and analysis for a 'biological effects' study. Mar. Ecol. Prog. Ser. 46: 213-226

Connell, J. H. (1978). Diversity in tropical rain forests and coral reefs. Science 199: 1302-1310

Dauvin, J.-C. (1984). Dynamique d'ecosystemes macrobenthiques des fonds sedimentaires de la Baie de Morlaix et leur perturbation par les hydrocarbures de l'AmocoCadiz. Ph.D. thesis, Univ. Pierre et Marie Curie, Paris
Dawson Shepherd, A. R., Warwick, R. M., Clarke, K. R., Brown, B. E. (1992). An analysis of fish community responses to coral mining in the Maldives. Environ. Biol. Fish. 33: $367-380$

Ferraro, S. P., Cole, F. A. (1990). Taxonomic level and sample size sufficient for assessing pollution impacts on the Southern California Bight macrobenthos. Mar. Ecol. Prog. Ser. $67: 251-262$

Gray, J S., Aschan, M., Carr, M. R., Clarke, K. R., Green. R. H., Pearson, T H., Rosenberg, R., Warwick, R. M (1988). Analysis of community attributes of the benthic macrofauna of Frierfjord/Langesundfjord and in a mesocosm experiment. Mar. Ecol. Prog. Ser. 46: 151-165

Gray, J. S., Clarke, K. R., Warwick, R. M., Hobbs, G. (1990). Detection of the initial effects of pollution on marine benthos: an example from the Ekofisk and Eldfisk oilfields, North Sea. Mar. Ecol. Prog. Ser. 66: 285-299

Heip, C., Warwick, R. M., Carr, M. R., Herman, P. M. J., Huys. R., Smol, N., van Holsbeke, K. (1988). Analysis of the community attributes of the benthic meiofauna in Frierfjord/ Langesundfjord. Mar. Ecol. Prog. Ser. 46: 171-180

Howson, C. M. (ed.) (1987). Directory of the British marine fauna and flora. A coded checklist of the marine fauna and flora of the British issles and its surrounding scas. Marine Conservation Society, Ross-on-Wye, Hertfordshire

Huston, M. (1979). A general hypothesis of species diversity. Am. Nat. 113: 81-101

Ibanez, F., Dauvin, J.-C. (1988). Long-term changes (1977-1987) in a muddy fine sand Abra alba-Melinna palmata community from the western English Channel: multivariate time-series analysis. Mar. Ecol. Prog. Ser. 49:65-81

Josefson, A. B. (1981). Persistence and structure of two deep macrobenthic communities in the Skagerrak (west coast of Sweden|. J. exp. mar. Biol. Ecol. 50: 63-97

Kruskal, J. B., Wish, M. (1978). Multidımensional scaling Sage Publications, Beverley Hills

Pearson, T. H. (1975). The benthic ecology of Loch Linnhe and Loch Eil, a sea-loch system on the west coast of Scotland. IV Changes in the benthic fauna attributable to organic enrichment. J. exp. mar. Biol. Ecol. 20: 1-41

Pearson, T. H. (1987). The benthic ecology of an accumulating sludge disposal ground. In: Capuzzo, J., Kester, D. (eds.) Biological processes and wastes in the ocean. R. E. Krieger, Melbourne, FL, p. 195-200

Pearson, T. H., Blackstock, J. (1984). Garroch Head sludge dumping ground survey, final report. Dunstaffnage Marine Research Laboratory, Oban

Rosenberg, R. (1972). Benthic faunal recovery in a Swedish fjord following the closure of a sulphite pulp mill. Oikos 23: $92-108$

Spence, I., Graef, J. (1974). The determination of the underlying dimensionality of an empirically obtained matrix of proximities. Multivar. Behav. Res. 9: 331-342

Warwick, R. M. (1986). A new method for detecting pollution effects on marine macrobenthic communities. Mar. Biol. 92: $557-562$

Warwick, R. M. (1988a). Analysis of community attributes of the macrobenthos of Frierfjord/Langesundfjord at taxonomic levels higher than species. Mar. Ecol. Prog. Ser. 46: $167-170$

Warwick, R. M. (1988b). The level of taxonomic discrimination required to detect pollution effects on marine benthic communties. Mar. Pollut. Bull. 19: 259-268

Warwick, R. M., Clarke, K. R. (1991). A comparison of some methods for analysing changes in benthic community structure. J. mar. biol. Ass. U.K. 71, 225-244

Warwick, R. M., Clarke, K. R., Suharsono. (1990). A statistical 
analysis of coral community responses to the 1982-83 El Niño in the Thousand Islands, Indonesia. Coral Reefs 8: $171-179$

Warwick, R. M., George, C. L., Davies, J. R. (1978). Annual macrofauna production in a Venus community. Estuar. coast. mar. Sci. 7: 215-241

This article was submitted to the editor
Warwick, R. M., Pearson, T. H., Ruswahyuni (1987). Detection of pollution effects on marine macrobenthos: further evaluation of the species abundance/biomass method. Mar Biol. 95: 193-200

Wu, R. S. S. (1982). Effects of taxonomic uncertainty on species diversity indices. Mar. environ. Res. 6: 215-225

Manuscript first received: March 3, 1992

Revised version accepted: November 30, 1992 